\title{
Prevalence and risk factors for shedding of thermophilic Campylobacter in calves with and without diarrhea in Austrian dairy herds
}

\author{
D. Klein, ${ }^{* 1}$ M. Alispahic, $†$ D. Sofka, $\ddagger$ M. Iwersen, ${ }^{*}$ M. Drillich, ${ }^{*}$ and F. Hilbert \\ *Section for Herd Health Management, Clinic for Ruminants, Department for Farm Animals and Veterinary Public Health, \\ †Clinic for Avian, Reptile and Fish Medicine, Department for Farm Animals and Veterinary Public Health, and \\ łInstitute of Meat Hygiene, Meat Technology and Food Science, Department for Farm Animals and Veterinary Public Health, University of \\ Veterinary Medicine Vienna, 1210 Vienna, Austria
}

\section{ABSTRACT}

The objectives of this study were to evaluate the presence of thermophilic Campylobacter in feces of calves with and without diarrhea on dairy farms and to survey farm characteristics and management practices to define risk factors for the presence of Campylobacter. Fifty dairy farms were chosen based on the presence of calf diarrhea, and 50 farms in which calves were free from diarrhea served as a standard of comparison. In total, fecal samples were taken from 382 calves. Farm data and management practices were surveyed using a questionnaire on farm. Campylobacter were isolated from fecal samples and colonies were identified by matrix-assisted laser desorption/ionization time-offlight mass spectrometry analysis. Campylobacter spp., mainly Campylobacter jejuni (93\% of isolated species), were detected on $33 \%$ of the farms and in $14.9 \%$ of the calves. Detection of Campylobacter did not differ between farms or between calves with and without diarrhea, although we found a tendency for calves suffering from diarrhea to shed Campylobacter more often. Calves may act as a reservoir of Campylobacter and may therefore lead to infections of other animals and humans. To define control strategies to reduce Campylobacter in calves, we identified on-farm risk factors. The presence of poultry on the farm, the time of cowcalf separation following birth, the use of an individual bucket for each calf, the feeding of waste milk, and the duration of individual housing were variables significantly associated with the appearance or absence of Campylobacter.

Key words: Campylobacter, calf, dairy herd, risk factor

Received July 27, 2012.

Accepted November 5, 2012.

${ }^{1}$ Corresponding author: Daniela.Klein@vetmeduni.ac.at

\section{INTRODUCTION}

Campylobacter has long been recognized as a pathogen and commensal organism of animals, and it is one of the most common causes of bacterial gastroenteritis in humans worldwide (Allos, 2001). Campylobacter species are widely distributed among animals. In contrast to most other animals, in which Campylobacter does not cause any symptoms, Campylobacter spp., especially Campylobacter jejuni, may cause diarrhea in calves (Al-Mashat and Taylor, 1983; Diker et al., 1990; Schulze, 1992). In addition to the potential risk of $\mathrm{Cam}$ pylobacter in contributing to enteritis in calves, calves might act as a reservoir for Campylobacter spp. and be a source of human infection, either by direct contact or through fecal contamination of food and water.

Little information is available on the prevalence of Campylobacter spp. in milk-fed dairy calves. Reported prevalence ranges from 11 to $36 \%$ (Achá et al., 2004; Grinberg et al., 2005), and inter-herd prevalence in young cattle up to the age of 1 yr varied between 47 and 97\% (Giacoboni et al., 1993; Ellis-Iversen et al., 2009a). Such data are not available for Austrian cattle herds.

Few risk factors for shedding of Campylobacter spp. by cattle have been described. Ellis-Iversen et al. (2009b) identified the presence of dairy cows on farm, drinking from a private water supply, feeding of hay, presence of horses, and indoor housing of young cattle as risk factors for shedding Campylobacter spp. in 3- to 17-moold cattle. In contrast, in adult cattle, outdoor housing was associated with the appearance of Campylobacter (Grove-White et al., 2010). In calves up to the age of 3 mo from cow-calf operations in Switzerland, animal's age, housing in open barns, herd size, and the feeding of more than $50 \%$ silage were identified as risk factors (Busato et al., 1999). In contrast, in young dairy calves up to the age of $15 \mathrm{~d}$, only group housing was described as a risk factor for harboring Campylobacter (WaltnerToews et al., 1986).

The aim of the present study was to evaluate the prevalence of thermophilic Campylobacter in feces of 
preweaned calves in Austrian dairy herds and to assess farm characteristics and management factors as possible risk factors associated with shedding of Campylobacter spp. Calves suffering from acute diarrhea were compared with healthy neighbor calves and to animals from farms without calf diarrhea.

\section{MATERIALS AND METHODS}

During 2009 and 2010, 100 dairy farms were visited in 2 regions of Austria (Lower Austria and Styria). In herds with a maximum of 5 preweaned calves, $100 \%$ of the animals were tested. On farms with more than 5 preweaned animals, 5 were randomly chosen. Assuming an inter-herd prevalence of over $40 \%$ (Giacoboni et al., 1993; Ellis-Iversen et al., 2009a), 5 samples were required from each herd to detect 1 positive calf with 95\% confidence (calculation by use of Win Episcope 2.0; www.clive.ed.ac.uk/winepiscope/). Fifty herds were chosen based on the history of calf diarrhea. In these farms, one or more calves were suffering from acute diarrhea at the time of the farm visit (hereafter "diseased" farms). Another 50 farms were included in the study where calves had been free from diarrhea for at least 6 wk (hereafter "healthy" farms). These farms were comparable in structure and geographic distribution to the diseased farms.

Farm management characteristics were evaluated by a face-to-face interview with the farmer during the farm visit by use of a questionnaire that included questions concerning farm structure, farm size, health status of the herd, calf housing, cleaning and disinfection of calf housing and calving areas, feeding of the calves, calving management, and common hygienic measures. The calf rearing area was inspected and hygiene was estimated by evaluation of calf housing (bedding and pen walls) and the calves themselves according to Lundborg et al. (2005).

The health status of each sampled calf was evaluated by clinical examination. Healthy calves had to be free from diarrhea, whereas sick calves showed signs of abnormal fecal consistency at the time of sampling. Feces were evaluated using the scoring system (scaled 1 to 4 ) published by Larson et al. (1977). Scores 3 and 4 were categorized as diarrhea. After clinical examination, a fecal sample was taken by gloved hand directly from the rectum and stored in a sterile plastic tube. Samples were transported cooled on ice to the laboratory and processed within a day.

\section{Laboratory Procedures}

For detection and isolation of thermophilic Campylobacter spp., fecal samples were analyzed according to the standards described by ISO-10272 (ISO, 2006).
In brief, fecal samples were enriched in Bolton broth (Oxoid, Basingstoke, UK) for $48 \mathrm{~h}$ at $42^{\circ} \mathrm{C}$ under microaerophilic conditions $\left(10 \% \mathrm{CO}_{2}, 5 \% \mathrm{O}_{2}\right.$, and $\left.85 \% \mathrm{~N}_{2}\right)$. A loopful of this enrichment was streaked onto modified charcoal cefoperazon deoxycholate agar (Oxoid) and a second loopful onto CampyFoodAgar (bioMérieux, Marcy l'Étoile, France). Both plates were incubated at $42^{\circ} \mathrm{C}$ for $48 \mathrm{~h}$ under microaerophilic conditions. Additionally, fecal material (without prior enrichment) was directly streaked on modified charcoal cefoperazon deoxycholate agar and CampyFoodAgar and incubated at $42^{\circ} \mathrm{C}$ for $48 \mathrm{~h}$. Morphological typical colonies were differentiated by aerobic incubation, PCR (Linton et al., 1997), and 16S rRNA gene sequencing on selected strains.

Campylobacter isolates were further identified and differentiated by matrix-assisted laser desorption/ ionization time-of-flight (MALDI-TOF) mass spectrometry analysis and Biotyper reference database version 3 (Bruker Daltonik GmbH, Leipzig, Germany) as described by Alispahic et al. (2010). For MALDI-TOF, colonies were grown on Columbia blood agar containing $5 \%$ sheep blood (bioMérieux) at $42^{\circ} \mathrm{C}$ for $48 \mathrm{~h}$ under microaerobic conditions. Single colonies were removed and analyzed.

\section{Statistical Analysis}

Data were analyzed statistically using PASW version 17.0 (IBM Corp., New York, NY). Descriptive statistics were calculated to describe farm characteristics and management practices. A 2-step process was used to assess the influence of different variables on the appearance of Campylobacter spp. on farms (herd level) and in calves (individual level).

Univariable regression tests were performed to analyze associations between Campylobacter status (negative $=$ 0 , positive $=1$ ) and each binary or categorical variable. $t$-Tests were performed to compare between continuous variables and the Campylobacter status. Variables with a $P$-value $\leq 0.2$ were included in a multiple logistic regression model, using Campylobacter status as outcome variable and farm as random effect. All variables (parametric and nonparametric) were tested for correlation by Pearson or Spearman rank correlation, respectively, before entering the model. If a correlation $(>60 \%)$ was found, one of the covariates was discarded, taking biological plausibility into account. A backward stepwise elimination of nonsignificant variables was performed to obtain a minimal model containing only significant variables $(P<0.05)$; independently of statistical significance, herd size was forced into the model as a proxy confounder. Model fit was evaluated with the Hosmer-Lemeshow test for 10 groups. 


\section{RESULTS}

\section{Shedding of Campylobacter}

The median number of dairy cows per farm was 36 , with a minimum of 5 and a maximum of 223 cows. The number of cattle per farm (categorical) and the distribution of Campylobacter related to herd size are shown in Table 1. In total, 382 calves from 100 dairy farms were enrolled in the study. In 62 herds, all preweaned calves were sampled, and on 91 herds, $\geq 50 \%$ of all preweaned calves on farm were sampled. The median age of examined calves was $17 \mathrm{~d}$, with a range of 1 to $69 \mathrm{~d}$. Percentages of sampled animals per farm are shown in Table 1. The detection rate of Campylobacter spp. did not differ with herd size $(P=0.75)$ or the proportion of sampled animals $(P=0.85)$.

Campylobacter spp. were detected in 57 of 382 fecal samples $(14.9 \%)$ and in $33 \%$ of the herds. On diseased farms, 79 diarrheic calves and 126 nondiarrheic calves were tested. The remaining 177 calves originated from healthy farms. Of the 79 diarrheic calves, 17 (21.5\%), and of the 303 healthy calves, 40 (13.2\%) shed Campylobacter spp. Campylobacter spp. could be diagnosed in $13 \%$ of the healthy and $20 \%$ of the diseased farms. The detection rate of Campylobacter did not differ significantly in healthy and diseased animals or between healthy and diseased farms $(P=0.06$ and $P=0.14$, respectively). Table 2 shows the distribution of Campylobacter spp. among herds and animals.

By use of PCR and MALDI-TOF/Biotyper analysis, 93\% (53/57) of all Campylobacter isolates were identified as $C$. jejuni. The remaining 4 isolates were identified as Campylobacter coli.

\section{Farm Characteristics and Risk Factors}

All calves were fed with milk, milk replacer, or both. Thirty-six percent of all examined calves received only liquid feed, whereas $64 \%$ of the animals were offered additional hay or grain. Most of the calves (304 calves, $80 \%$ ) were housed in individual calf hutches or igloos. The remaining 20\% were housed in groups of 2 to 30 animals. Concerning the site of housing, 169 calves (44\%) were housed within the cow stable, 99 (26\%) in facilities for calves and young stock, and 30\% (114 animals) outdoors.

The univariable analysis revealed that at the herd level, the presence of poultry was associated with the shedding of Campylobacter spp. [odds ratio (OR) 2.54, 95\% CI: 1.08-5.97; $P=0.03$; Table 3]. Furthermore, the time of cow-calf separation after birth had an influence. Herds in which calves were left with their dam for more than $1 \mathrm{~h}$ had a 2.62 higher risk for being Campylobacter positive than herds in which calves were separated from the cow immediately after birth (OR 2.62, 95\% CI: $1.02-6.74 ; P=0.05$; Table 3$)$. At the individual level, the presence of poultry also showed an association with the presence of Campylobacter in calves (OR 2.14, 95\% CI: $1.21-3.79 ; P=0.01$; Table 4). Additionally, feeding of waste milk (OR 0.47, 95\% CI: $0.24-0.92 ; P=0.03)$ and the duration of individual housing (OR $0.98,95 \%$ CI: $0.96-0.99 ; P<0.01$ ) were negatively associated with shedding of Campylobacter (Table 4).

At the herd level, the following variables with a $P$ value $\leq 0.2$ at univariable analysis were used in a multiple logistic regression model: presence or absence of diarrhea, presence of poultry and farm animals others

Table 1. Number of cattle, preweaned calves, and sampled animals per farm and distribution of Campylobacter spp. on 100 dairy farms in Austria $^{1}$

\begin{tabular}{|c|c|c|c|c|c|c|}
\hline \multirow[b]{2}{*}{ Variable } & \multirow[b]{2}{*}{ Category } & \multirow[b]{2}{*}{ No. } & \multicolumn{4}{|c|}{ Campylobacter spp. } \\
\hline & & & No. & $\%$ & No. & $\%$ \\
\hline Herd size/total no. of cattle on farm (categorical) & $\begin{aligned} & 1-50 \\
& 51-100 \\
& 101-150 \\
&> 150\end{aligned}$ & $\begin{array}{r}28 \\
48 \\
17 \\
7\end{array}$ & $\begin{array}{r}10 \\
14 \\
6 \\
3\end{array}$ & $\begin{array}{l}36 \\
29 \\
35 \\
43\end{array}$ & $\begin{array}{r}18 \\
34 \\
11 \\
4\end{array}$ & $\begin{array}{l}64 \\
71 \\
65 \\
57\end{array}$ \\
\hline No. of preweaned calves on farm (categorical) & $\begin{aligned} & 1-5 \\
& 6-10 \\
& 11-15 \\
&> 15\end{aligned}$ & $\begin{array}{r}63 \\
28 \\
6 \\
3\end{array}$ & $\begin{array}{r}22 \\
7 \\
3 \\
1\end{array}$ & $\begin{array}{l}35 \\
25 \\
50 \\
33\end{array}$ & $\begin{array}{r}41 \\
21 \\
3 \\
2\end{array}$ & $\begin{array}{l}65 \\
75 \\
50 \\
67\end{array}$ \\
\hline Proportion (\%) of sampled calves (categorical) & $\begin{array}{l}100 \\
75-99 \\
50-74 \\
<50\end{array}$ & $\begin{array}{r}62 \\
11 \\
18 \\
9\end{array}$ & $\begin{array}{r}22 \\
3 \\
4 \\
4\end{array}$ & $\begin{array}{l}35 \\
27 \\
22 \\
44\end{array}$ & $\begin{array}{r}40 \\
8 \\
14 \\
5\end{array}$ & $\begin{array}{l}65 \\
73 \\
78 \\
56\end{array}$ \\
\hline
\end{tabular}

${ }^{1}$ No statistical significant differences were detected in the presence of Campylobacter spp. on farm in regard to herd size, number of preweaned calves, and proportion of sampled calves $(P>0.05)$. 
Table 2. Occurrence of Campylobacter spp. in the feces of diarrheic and healthy calves on 100 dairy farms in Austria $^{1}$

\begin{tabular}{|c|c|c|c|c|c|}
\hline \multirow[b]{3}{*}{ Item } & \multirow[b]{3}{*}{ Number } & \multicolumn{4}{|c|}{ Campylobacter spp. } \\
\hline & & \multicolumn{2}{|c|}{ Positive } & \multicolumn{2}{|c|}{ Negative } \\
\hline & & No. & $\%$ & No. & $\%$ \\
\hline Calves & 382 & 57 & 14.9 & 325 & 85.1 \\
\hline Farms & 100 & 33 & 33.0 & 67 & 67.0 \\
\hline Farms with diarrhea & 50 & 20 & 40.0 & 30 & 60.0 \\
\hline Farms without diarrhea & 50 & 13 & 26.0 & 37 & 74.0 \\
\hline Calves from farms with diarrhea & 205 & 34 & 16.6 & 171 & 83.4 \\
\hline Calves from farms without diarrhea & 177 & 23 & 13.0 & 154 & 87.0 \\
\hline Calves with diarrhea & 79 & 17 & 21.5 & 62 & 78.5 \\
\hline Calves without diarrhea & 303 & 40 & 13.2 & 263 & 86.8 \\
\hline
\end{tabular}

${ }^{1}$ No statistical significant differences were detected between any of the groups $(P>0.05)$.

than poultry or swine (e.g., goat, sheep), presence of horses, animal caretaker, site of group housing, birth in a calving pen or not, separation of calf and dam following birth, and use of a separate bucket for each calf (Table 3). Of these 9 variables initially included in the model, 3 remained significant $(P<0.05)$. The presence of poultry on the farm was associated with the occurrence of Campylobacter spp. in calves (OR 5.21,
95\% CI: $1.82-14.92 ; P<0.01)$. Furthermore, calves left with their dam in the maternity pen after birth were at a higher risk of shedding Campylobacter spp. compared with calves that were removed to individual housing immediately (OR 4.03, 95\% CI: $1.37-11.82 ; P=0.01$ ). Feeding each calf from an individual bucket or not also had a significant effect on Campylobacter detection in calf feces. Feeding each calf from its own bucket pro-

Table 3. Results of the univariable analysis on herd level with Campylobacter presence (positive/negative) as independent variable ${ }^{1}$

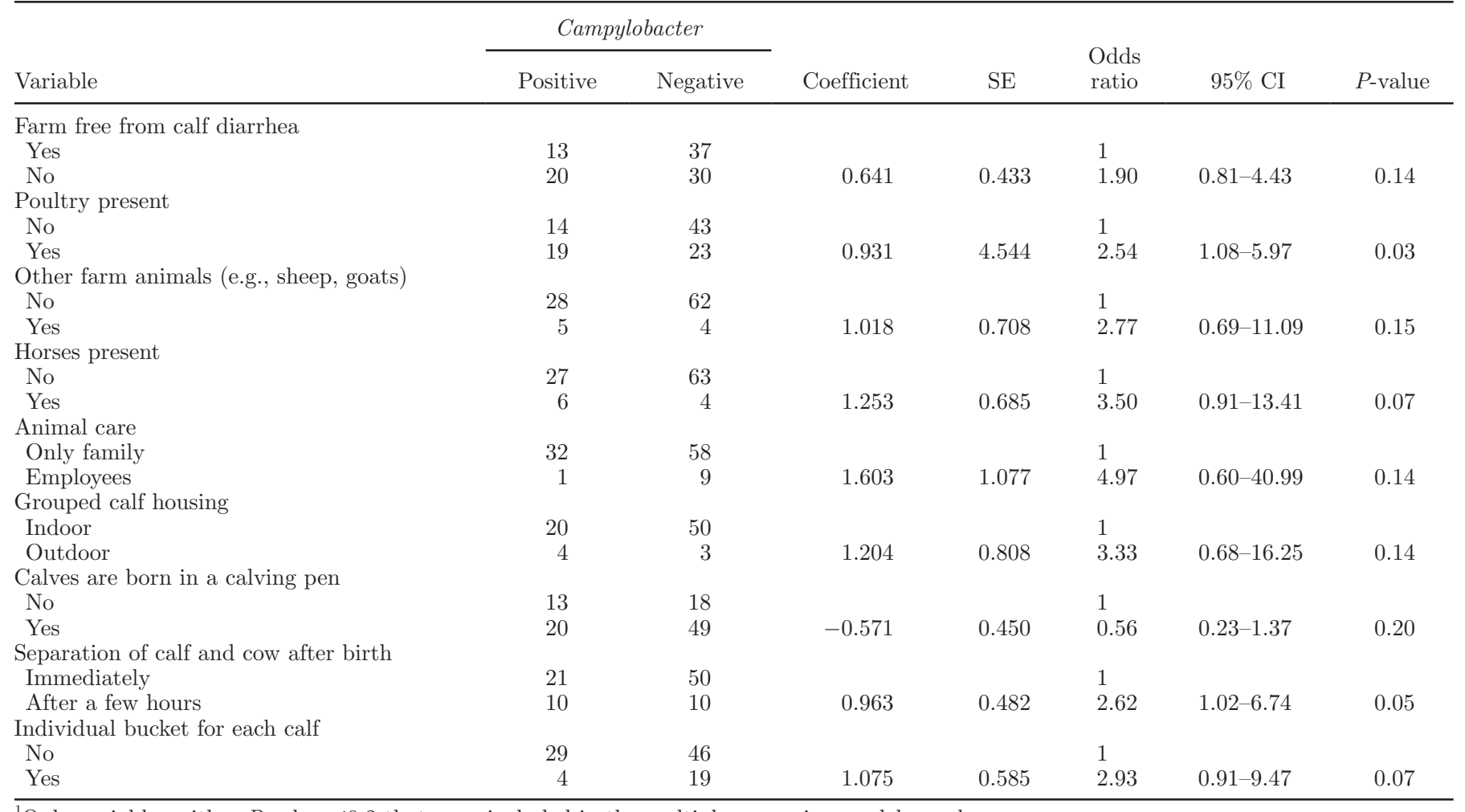

${ }^{1}$ Only variables with a $P$-value $\leq 0.2$ that were included in the multiple regression model are shown. 
Table 4. Results of univariable analysis on individual level with Campylobacter presence (positive/negative) as independent variable ${ }^{1}$

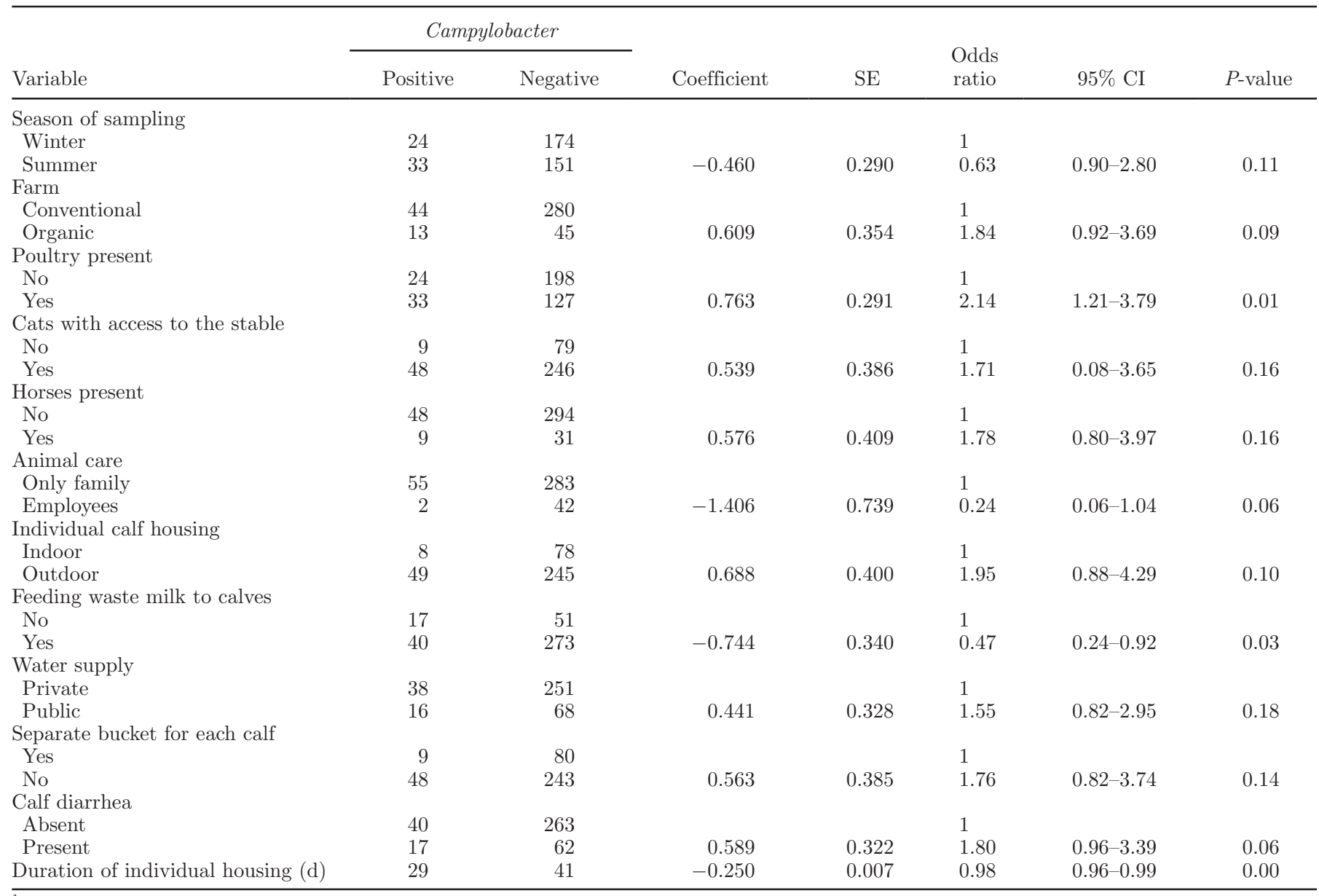

${ }^{1}$ Only variables with a $P$-value $\leq 0.2$ that were included in the multiple regression model are presented.

tected it from being Campylobacter positive (OR 0.20, 95\% CI: $0.05-0.77 ; P=0.02$; Table 5).

At the individual level, 12 variables with a $P$-value $\leq 0.2$ were included in the multiple model: season, type of farm (conventional or organic), presence of poultry, cats with access to the stable, presence of horses, animal caretaker, place of individual calf housing (indoor vs. outdoor), feeding of waste milk to calves, private or public water supply, use of a separate bucket for each calf, calf diarrhea, and duration of individual housing of calves (Table 5). In the final model, the presence of poultry (OR 2.34, 95\% CI: 1.17-4.68; $P=0.02$ ), the feeding of calves with waste milk (OR 0.37, 95\% CI: $0.17-0.84 ; P=0.02)$, and the length of individual housing (OR 0.98, 95\% CI: 0.97-0.99; $P=0.02$ ) were significant (Table 6). The presence of poultry was identified as a risk factor, whereas calves fed waste milk had a lower risk for shedding of Campylobacter and the longer calves were housed individually, the lower their chance of being Campylobacter positive.

\section{DISCUSSION}

In this study, the proportion of Campylobacter shedding calves was $14.9 \%$, within the range of previously reported prevalence, although higher values (up to 38\%) have been described (Busato et al., 1999; Grinberg et al., 2005). A possible explanation for these findings could originate in management after birth. For example, time that calves spent with their dam turned out to be a risk factor for the shedding of Campylobacter. In contrast to our study, calves in these earlier studies (Busato et al., 1999; Grinberg et al., 2005) were mainly left with their dam. Furthermore, calves in these prior studies were group-housed, a variable positively associated with Campylobacter shedding (Waltner-Toews et al., 1986). Another explanation could be an underestimation of the true prevalence in our study because a maximum of 5 animals were tested on each farm. However, on more than half of the farms studied, these calves represented $100 \%$ of the preweaned calves, and on almost all the 
Table 5. Multiple analysis of risk factors for the appearance of Campylobacter jejuni and Campylobacter coli in calves on a herd level ${ }^{1}$

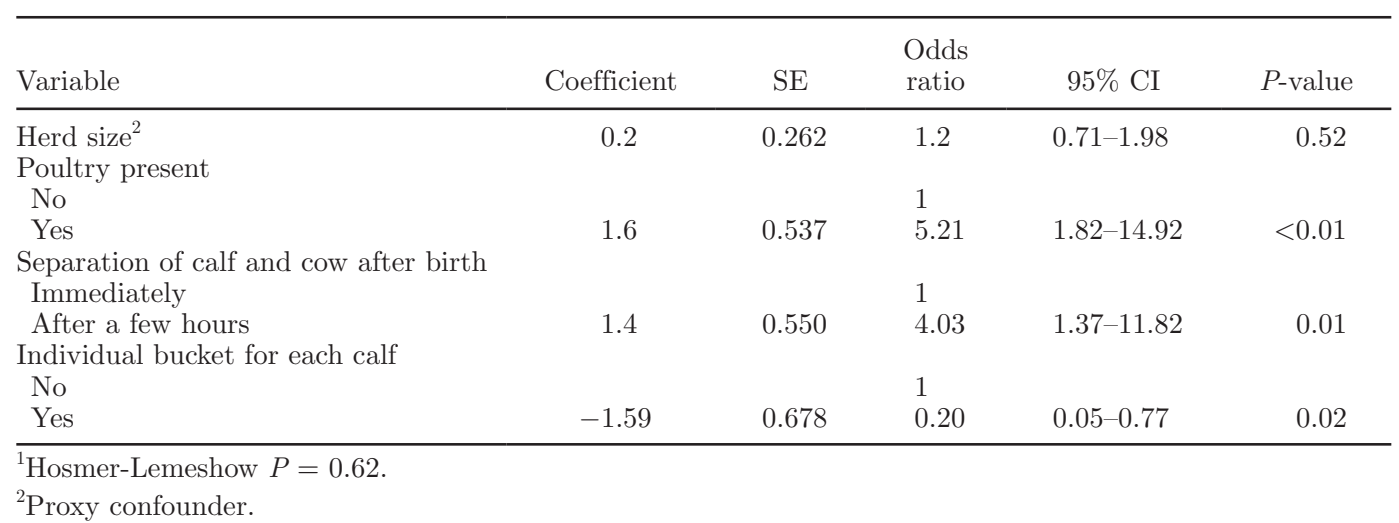

farms (91\%), more than half of the calves were enrolled in the study.

Shedding of Campylobacter spp. did not differ between healthy and diarrheic calves or between farms with presence or absence of diarrhea; however, on an individual level, we observed a tendency that diarrheic calves shed Campylobacter more frequently than healthy calves ( 21.5 vs. $13.2 \% ; P=0.06)$. Nevertheless, it has to be taken into account that the number of diarrheic calves was low compared with healthy calves. Similar results were obtained by Adesiyun et al. (1992) concerning diarrheic calves. In contrast, De Rycke et al. (1986) and Achá et al. (2004) could not find any difference in shedding of Campylobacter between diarrheic and nondiarrheic calves. Our results support the hypothesis that Campylobacter might be one contributor to enteritis in calves but does not seem to be a major pathogen. This hypothesis should be confirmed by infection studies. The youngest calf that shed $\mathrm{Cam}$ pylobacter in the present study was only $3 \mathrm{~d}$ of age. Early infection could be due to contamination of the calving area because the time spent in this area was a risk factor.
Cattle may be a source for human infection either by direct contact (Eberhart-Phillips et al., 1997; Smith et al., 2004) or by environmental contamination. Until now, the importance of cattle in the epidemiology of Campylobacter has not been well understood. Critical control points to reduce shedding of Campylobacter in cattle herds are largely unknown. To establish intervention strategies on farm, knowledge of risk factors associated with the appearance of Campylobacter is essential.

In the current study, the presence of poultry was significantly associated with the shedding of Campylobacter in calves. Poultry are known to be the most important reservoir of Campylobacter and, as in poultry, C. jejuni was the predominant species in calves. Not only are cattle at risk of being infected by poultry, but cattle have been described as a risk factor for infection of broiler flocks (Hansson et al., 2010). We found no association between Campylobacter in calves and the presence of other animals such as sheep, goats, pigs, equines, and pets on farm.

Another variable associated with the appearance of Campylobacter was the time between separation of calf

Table 6. Multiple analysis of risk factors for the appearance of Campylobacter jejuni and Campylobacter coli in calves on an individual level with farm as cluster effect ${ }^{1}$

\begin{tabular}{lccccc}
\hline Variable & Coefficient & SE & $\begin{array}{c}\text { Odds } \\
\text { ratio }\end{array}$ & $95 \%$ CI & $P$-value \\
\hline $\begin{array}{l}\text { Herd size } \\
\text { Poultry present }\end{array}$ & 0.621 & 0.680 & 1.86 & $0.49-7.06$ & 0.39 \\
$\quad$ No & & & 1 & & \\
$\quad$ Yes & 0.852 & 0.353 & 2.34 & $1.17-4.68$ & 0.02 \\
$\quad$ Feeding waste milk to calves & & & & & \\
$\quad$ No & -0.987 & 0.414 & 0.37 & $0.17-0.84$ & 0.02 \\
$\quad$ Yes & -0.018 & 0.008 & 0.98 & $0.97-0.99$ & 0.02 \\
$\quad$ Time of individual housing (d) & & & & & \\
$\quad{ }^{1}$ Hosmer-Lemeshow $P=0.26$. & & & & &
\end{tabular}


and cow after birth. The odds of becoming Campylobacter positive was 4.03 times higher on farms in which calves were not immediately separated from their dams compared with farms where calves were immediately separated. A possible explanation could be that in stress situations (e.g., calving), cows shed Campylobacter more often and in greater amounts (Stanley et al., 1998), leading to a large environmental load that might infect newborn calves. Another risk factor could be the transmission of bacteria by suckling. The route of infection might be by fecal contamination rather than via milk itself (Hakkinen and Hanninen, 2009). Thus, the advice to transfer calves as quickly as possible from the calving area or herd to clean, individual housing could be important in reducing Campylobacter infection of calves.

Calves from farms on which animals were fed with an individual bucket were at a lower risk of being Campylobacter positive, supporting the hypothesis that Campylobacter could be spread by contamination of the bucket teat. Artificial teats are not usually cleaned between calves when the buckets are used for multiple animals. On the individual calf level, the feeding of waste milk was associated with the shedding of Campylobacter. Namely, calves fed waste milk showed a lower prevalence of Campylobacter than calves not fed waste milk. A possible explanation could be antibiotic residues present in the milk and the competition between Campylobacter and other bacteria that are usually higher in numbers in waste milk. This finding should be elucidated in further studies. Furthermore, milk composition and $\mathrm{pH}$ may change due to disease of the mammary gland or because of drug treatment and therefore negatively affect the survival of Campylobacter (Moore et al., 2000; Chaveerach et al., 2003; Doyle and Erickson, 2006).

\section{CONCLUSIONS}

Although it had been assumed that Campylobacter spp. could lead to diarrhea in calves, the data from the current study suggest that Campylobacter spp. do not play a major role in diarrhea of calves. However, Campylobacter spp. were found in $33 \%$ of the examined farms, suggesting that calves may act as a reservoir for Campylobacter, especially C. jejuni, which may lead to infection of other animals and humans. Further research is required to elucidate these interactions. To establish on-farm intervention strategies to reduce the shedding of Campylobacter, risk factors associated with the presence of Campylobacter have to be determined. The following variables were associated with Campylobacter shedding in calves: presence of poultry on the farm, length of time in the calving area, use of a shared feeding bucket, and the time of individual housing; these factors should be decreased or eliminated to reduce Campylobacter shedding in calves.

\section{ACKNOWLEDGMENTS}

This study was financed by the University of Veterinary Medicine Vienna (Austria) by a start-up project (Profillinie 2).

\section{REFERENCES}

Achá, S. J., I. Kuhn, P. Jonsson, G. Mbazima, M. Katouli, and R. Mollby. 2004. Studies on calf diarrhoea in Mozambique: Prevalence of bacterial pathogens. Acta Vet. Scand. 45:27-36.

Adesiyun, A. A., J. S. Kaminjolo, R. Loregnard, and W. Kitson-Piggott. 1992. Campylobacter infections in calves, piglets, lambs and kids in Trinidad. Br. Vet. J. 148:547-556.

Al-Mashat, R. R., and D. J. Taylor. 1983. Production of enteritis in calves by the oral inoculation of pure cultures of Campylobacter fetus subspecies intestinalis. Vet. Rec. 112:54-58.

Alispahic, M., K. Hummel, D. Jandreski-Cvetkovic, K. Nobauer, E. Razzazi-Fazeli, M. Hess, and C. Hess. 2010. Species-specific identification and differentiation of Arcobacter, Helicobacter and Campylobacter by full-spectral matrix-associated laser desorption/ionization time of flight mass spectrometry analysis. J. Med. Microbiol. $59: 295-301$.

Allos, B. M. 2001. Campylobacter jejuni infections: Update on emerging issues and trends. Clin. Infect. Dis. 32:1201-1206.

Busato, A., D. Hofer, T. Lentze, C. Gaillard, and A. Burnens. 1999. Prevalence and infection risks of zoonotic enteropathogenic bacteria in Swiss cow-calf farms. Vet. Microbiol. 69:251-263.

Chaveerach, P., A. A. ter Huurne, L. J. Lipman, and F. van Knapen. 2003. Survival and resuscitation of ten strains of Campylobacter jejuni and Campylobacter coli under acid conditions. Appl. Environ. Microbiol. 69:711-714.

De Rycke, J., S. Bernard, J. Laporte, M. Naciri, M. R. Popoff, and A. Rodolakis. 1986. Prevalence of various enteropathogens in the feces of diarrheic and healthy calves. Ann. Rech. Vet. 17:159-168.

Diker, K. S., S. Diker, and M. B. Ozlem. 1990. Bovine diarrhea associated with Campylobacter hyointestinalis. Zentralbl. Veterinarmed. B. 37:158-160.

Doyle, M. P., and M. C. Erickson. 2006. Reducing the carriage of foodborne pathogens in livestock and poultry. Poult. Sci. 85:960-973.

Eberhart-Phillips, J., N. Walker, N. Garrett, D. Bell, D. Sinclair, W. Rainger, and M. Bates. 1997. Campylobacteriosis in New Zealand: Results of a case-control study. J. Epidemiol. Community Health 51:686-691.

Ellis-Iversen, J., A. J. Cook, R. P. Smith, G. C. Pritchard, and M. Nielen. 2009a. Temporal patterns and risk factors for Escherichia coli O157 and Campylobacter spp. in young cattle. J. Food Prot. $72: 490-496$

Ellis-Iversen, J., G. C. Pritchard, M. Wooldridge, and M. Nielen. 2009b. Risk factors for Campylobacter jejuni and Campylobacter coli in young cattle on English and Welsh farms. Prev. Vet. Med. 88:42-48

Giacoboni, G. I., K. Itoh, K. Hirayama, E. Takahashi, and T. Mitsuoka. 1993. Comparison of fecal Campylobacter in calves and cattle of different ages and areas in Japan. J. Vet. Med. Sci. 55:555-559.

Grinberg, A., W. E. Pomroy, J. F. Weston, A. Ayanegui-Alcerreca, and D. Knight. 2005. The occurrence of Cryptosporidium parvum, Campylobacter and Salmonella in newborn dairy calves in the Manawatu region of New Zealand. N. Z. Vet. J. 53:315-320.

Grove-White, D. H., A. J. Leatherbarrow, P. J. Cripps, P. J. Diggle, and N. P. French. 2010. Temporal and farm-management-associated variation in the faecal-pat prevalence of Campylobacter jejuni in ruminants. Epidemiol. Infect. 138:549-558. 
Hakkinen, M., and M. L. Hanninen. 2009. Shedding of Campylobacter spp. in Finnish cattle on dairy farms. J. Appl. Microbiol. 107:898-905

Hansson, I., E. O. Engvall, I. Vagsholm, and A. Nyman. 2010. Risk factors associated with the presence of Campylobacter-positive broiler flocks in Sweden. Prev. Vet. Med. 96:114-121.

ISO. 2006. ISO/TS 10272: Microbiology of food and animal feeding stuffs-Horizontal method for detection and enumeration of $\mathrm{Cam}$ pylobacter spp. Part 2: Colony-count technique. International Organization for Standardization (ISO), Geneva, Switzerland.

Larson, L. L., F. G. Owen, R. D. Albright, R. D. Appleman, R. C. Lamb, and L. D. Miller. 1977. Guidelines toward more uniformity in measuring and reporting calf experimental data. J. Dairy Sci. 60:989-991.

Linton, D., A. J. Lawson, R. J. Owen, and J. Stanley. 1997. PCR detection, identification to species level, and fingerprinting of Campylobacter jejuni and Campylobacter coli direct from diarrheic samples. J. Clin. Microbiol. 35:2568-2572.

Lundborg, G. K., E. C. Svensson, and P. A. Oltenacu. 2005. Herd-level risk factors for infectious diseases in Swedish dairy calves aged 0-90 days. Prev. Vet. Med. 68:123-143.
Moore, S. J., M. J. VandeHaar, B. K. Sharma, T. E. Pilbeam, D. K. Beede, H. F. Bucholtz, J. S. Liesman, R. L. Horst, and J. P. Goff. 2000. Effects of altering dietary cation-anion difference on calcium and energy metabolism in peripartum cows. J. Dairy Sci 83:2095-2104.

Schulze, F. 1992. Campylobacter as the cause of diarrhea in calves. Dtsch. Tierarztl. Wochenschr. 99:458-461.

Smith, K. E., S. A. Stenzel, J. B. Bender, E. Wagstrom, D. Soderlund, F. T. Leano, C. M. Taylor, P. A. Belle-Isle, and R. Danila. 2004. Outbreaks of enteric infections caused by multiple pathogens associated with calves at a farm day camp. Pediatr. Infect. Dis. J. 23:1098-1104.

Stanley, K. N., J. S. Wallace, J. E. Currie, P. J. Diggle, and K. Jones. 1998. The seasonal variation of thermophilic Campylobacters in beef cattle, dairy cattle and calves. J. Appl. Microbiol. 85:472480.

Waltner-Toews, D., S. W. Martin, and A. H. Meek. 1986. An epidemiological study of selected calf pathogens on Holstein dairy farms in Southwestern Ontario. Can. J. Vet. Res. 50:307-313. 